\title{
CULTURE-BOUND WORDS AS A METHOD OF SPEECH STRATEGIES IN GERMAN POLITICAL DISCOURSE
}

\author{
Aleksandra P. Kryachkova \\ Moscow State Institute of International Relations (University), \\ 76, Prospect Vernadskogo, Moscow, 119454, Russia
}

\begin{abstract}
The article is devoted to the study of culture-bound words as a method of verbal strategies of political discourse, aimed at both maintaining a positive image and verbal attacks against opponents and competing political parties. The relevance of research is due to insufficient knowledge of the lexical units with a national-cultural component from the standpoint of political linguistics. The material for the study included the speeches of the ruling parties' leaders in Germany: Angela Merkel (Christian Democratic Union) and Horst Seehofer (Christian Social Union) in the context of the "Political Ash Wednesday" 2017. Politicians' statements containing culture-bound words were selected by continuous sampling method. The analysis revealed that the speakers deliberately used culture-bound words in order to implement their communicative intentions. Such units illustrate non-linguistic reality; they are directly related to the values of society and influence the recipient in communication. Using the statements of A. Merkel and H. Seehofer, the author identified five speech strategies (self-presentation and discredit strategies, informationinterpretation, manipulative and agitation strategies), and also established their relationship with the use of culture-bound words.
\end{abstract}

Key Words: political discourse, public speaking, image, speech strategies, culture-bound words, means of language

For citation: Kryachkova A.P. 2020. Culture-bound Words as a Method of Speech Strategies in German Political Discourse. Philological Sciences at MGIMO. Vol. 6. No 4(24). P. 25-35. https://doi. org/10.24833/2410-2423-2020-4-24-25-35

\section{КУЛЬТУРНО-МАРКИРОВАННАЯ ЛЕКСИКА КАК ПРИЁМ РЕЧЕВЫХ СТРАТЕГИЙ В ПОЛИТИЧЕСКОМ ДИСКУРСЕ ГЕРМАНИИ}

\begin{abstract}
А.П. Крячкова
Московский государственный институт международных отношений (университет) МИД России, 119454, Москва, пр. Вернадского, 76
\end{abstract}

\footnotetext{
1 Статья подготовлена в рамках гранта Х Конкурса молодых ученых МГИМО № КМУ-10/09
} 
Аннотация. Настоящая статья посвящена исследованию культурно-маркированной тексики как приёма речевых стратегий политического дискурса, направленных как на поддержание позитивного имиджа, так и на совершение вербальных атак в адрес оппонентов и конкурирующих политических партий. Актуальность данной работы обусловлена недостаточной изученностью роли лексических единич с начионально-культурным компонентом с позииий политической лингвистики. Материалом для исследования послужили выступления лидеров правящих партий ФРГ: Ангель Меркель (Христианско-демократический союз) и Хорста Зеехофера (Христианско-соииальный союз) в рамках “политической пепельной средь” 2017 года. Высказывания политиков, содержащие культурно-маркированную лексику, были отобраны методом сплошной выборки. В ходе проведённого анализа было выявлено сознательное использование ораторами культурно-маркированной лексики с целью реализации своих коммуникативных намерений. Такие лексические единицы иллюстрируют внеязыковую реальность, напрямую связань с иенностньми ориентирами общества и оказывают влияние на массового адресата в ходе коммуникации. На примере выступлений А. Меркель и Х. Зеехофера автор выявил пять речевых стратегий (стратегии самопрезентации и дискредитации, информационно-интерпретаиионная, манипулятивная и агитационная стратегии), а также установил их взаимосвязь с употреблением культурно-маркированной лексики.

Ключевые слова: политический дискурс, публичные выступления, имидж, речевые стратегии, культурно-маркированная лексика, языковые средства

Для цитирования: Крячкова А.П. 2020. Культурно-маркированная лексика как приём речевых стратегий в политическом дискурсе германии. Филологические науки в МГИМО. Том 6. № 4(24). C. 25-35. https://doi.org/10.24833/2410-2423-2020-4-24-25-35

$\mathrm{K}$ ультурно-маркированная лексика (далее - КМЛ) представляет собой совокупность языковых единиц, обозначающих понятия, характерные для отдельного народа, отражающие его историю и особенности культуры. Данная лексика связана с культурным самосознанием общества, поскольку передаёт образ мышления представителей народа [12, с. 14]. Исследование КМЛ всегда привлекало внимание учёных. Так, Е.М. Верещагин и В.Г. Костомаров классифицировали этот пласт по уровням и выделяли: безэквивалентную, фоновую и коннотативно-маркированную лексику [2]. Реалии на материале английского языка изучал Г.Д. Томахин, его классификация включает географические, общественно-политические и этнографические реалии [13]. Способность языковых единиц отражать культурный компонент анализировали И.Е. Аверьянова, В.И. Карасик, Д.Г. Мальцева, Ю.К. Караулов, Г.Д. Томахин, Н.Е. Меркиш, А.В. Кунин и др. Однако все предпринимаемые ранее исследования, как правило, описывали КМЛ в рамках одной лингвистической теории и не учитывали специфику различных профессиональных дискурсов.

Представляется актуальным рассмотреть употребление КМЛ с позиций политической коммуникации и политической лингвистики. Политическая коммуникация как вид институционального дискурса представляет собой вербальную коммуникацию, в которой интерактанты наделяются социальными ролями в зависимости от их участия в политической жизни, а предметом общения становится политическая жизнь общества [4].

Борьба за власть является основной задачей политического дискурса и определяет его основную функцию - воздействие на массового адресата посредством убеждения [8]. Таким образом, успешность реализации поставленных целей в процессе выступления политического деятеля напрямую зависит от выбора лингвистических средств. По мнению А.П. Чудинова, к особенностям политического языка относятся смысловая неопределённость, иррациональность высказываний, театральность и дистанцированность [15]. Е.И. Шейгал отмечает, что в речевых актах политиков преобладают также оценочные и манипулятивные суждения, содержащие в себе ценностные концепты [16]. Поскольку темой политического обсуждения может стать любая сфера деятельности (экономика, образование, защита окружающей среды и др.), политический дискурс характеризуется многообразием и часто включает в себя понятия, изначально не связанные с политической сферой. 
В связи с этим, изучение КМЛ в рамках политической лингвистики позволяет глубже понять происходящие политические процессы и проанализировать цели и задачи речевых действий политических акторов. Особый интерес представляет фоновая лексика, для которой характерен культурный компонент или лексический фон [2]. Культурный компонент значения содержится в семантике слов, «совпадающих на поверхности в своих лексических значениях, но резко отличающихся значениями культурными» $[3$, с. 55].

Цель данной статьи заключалась в рассмотрении КМЛ как приёма речевых стратегий в речи партийно-политических деятелей, в определении влияния подобных единиц на формирование собственного политического имиджа и имиджа конкурентов.

Для достижения поставленной цели использовались методы компонентного и контекстуального анализа, а также описательно-аналитический метод с включением приёмов интерпретации и систематизации анализируемого корпуса примеров.

В качестве материала исследования были выбраны речи лидеров правящего блока ХДС/ХCС: выступление Ангелы Меркель ${ }^{2}$ (ХДС) и Хорста Зеехофера ${ }^{3}$ (ХСС) 1 марта 2017 г. в рамках “политической пепельной среды” (politischer Aschermittwoch). В немецком политическом дискурсе так называют традиционные собрания различных партий, проводимые в последний день весеннего карнавала (Aschermittwoch). Видеозапись выступлений размещена на сайте youtube.com, объём звучания речи А. Меркель составляет 24 мин. 24 сек., речи Х. Зеехофера - 58 мин. 95 сек. Речи политиков были прослушаны и записаны в форме печатного текста, общий объём скриптов - 1,2 а.л.

Выбор данных временных рамок обусловлен внеязыковым фактором: в сентябре 2017 года проходили выборы в бундестаг, что является значимым политическим событием для германского общества, в преддверии этих выборов каждая партия старается оказать максимально возможное влияние на решение избирателей, преимущественно вербальными средствами.

\section{Публичное выступление и речевые стратегии}

В современной лингвистике существует множество жанровых классификаций политического текста. Е.И. Шейгал выделяет возможность определения отдельного жанра по следующим параметрам: степень прототипности, событийная локализация, социокультурная специфика, субъектно-адресные отношения и уровень институциональности [16].

В данной статье мы опираемся на классификацию Е.Ю. Алешиной, основанной на целеполагающей характеристике политического текста:

• информационный жанр (инаугурационные речи, послания конгрессу, выступления в парламенте и др.);

• убеждающий жанр (речь на съезде/собрании, предвыборные выступления и др.);

- призывный жанр (предвыборная речь, публичное выступление, заявление и др.);

- жанр - оправдание/покаяние (публичная речь покаяния, речь-оправдание).

Выделенные жанры часто носят смешанный характер, поскольку в ходе выступления политический деятель может реализовывать несколько интенций [1, c. 45]. В соответствии с данной классификацией анализируемые в данной статье публичные выступления в равной степени относятся к убеждающему и призывному жанрам.

Мероприятия “политической пепельной среды” имеют в Германии важное культурное и политическое значение. В ходе выступлений политики затрагивают важные для общества темы и критикуют действия конкурирующих партий с целью снизить их влияние на массового адресата. Таким образом, в рамках публичных выступлений ораторы реализуют две основные интенции борьбы за власть: поддержание собственного имиджа и нарушение имиджа оппонентов. Для дис-

\footnotetext{
Angela Merkel beim 22. Politischen Aschermittwoch der CDU Mecklenburg-Vorpommern https://www.youtube.com/watch?v=fjjHuOtCD_Q

Politischer Aschermittwoch: Rede von Horst Seehofer am 01.03.2017 https://www.youtube.com/watch?v=VAsBGbAvCPE
} 
кредитации конкурирующей партии оратор может прибегать к обвинительным и оскорбляющим речевым действиям, в то время как для сохранения имиджа в глазах потенциального электората могут быть использованы речевые действия самовосхваления или самозащиты.

Успешность реализации интенций адресанта зависит от выбранной им речевой стратегии и тактики. О.С. Иссерс определяет речевую стратегию как совокупность речевых действий, направленных на достижение коммуникативной цели, а речевую тактику - как конкретные коммуникативные действия, способствующие реализации стратегии [5].

На данный момент не существует единой классификации стратегий и относящихся к ним тактик, однако большинство лингвистов выделяют следующие речевые стратегии: стратегия дискредитации, манипулятивные стратегии, стратегия самозащиты, самопрезентации, агитационная стратегия (Т. Дейк ван, О.С. Иссерс, О.Н. Паршина, В.И. Карасик и др.).

Ж.В. Зигманн подчёркивает, что постоянное развитие политического дискурса и необходимость быстрой реакции на происходящие изменения в политической жизни общества обуславливает выбор речевых стратегий и одновременность их использования в ходе коммуникации [4].

\section{Реализация речевых стратегий в выступлениях консервативных политиков}

Выступления политиков в рамках “политической пепельной среды” направлены на укрепление собственных позиций и создание позитивного имиджа в глазах потенциальных избирателей. Положительный имидж партии и отдельного политического деятеля должен соответствовать ожиданиям социальной среды, поэтому ораторы апеллируют к близким и понятным для общества ценностям [9]. Данный коммуникативный приём позволяет политикам сформировать позитивный эмоциональный настрой, необходимый для отождествления с массовым адресатом. Рассмотрим примеры реализации различных речевых стратегий в выступлениях А. Меркель и Х. Зеехофера.

Стратегия самопрезентации служит для создания положительного образа адресанта и актуализации доверия аудитории. Среди наиболее употребляемых тактик можно выделить тактику создания «своего круга» и тактику отождествления. Распространённым приёмом для реализации стратегии самопрезентации в анализируемых текстах стало употребление эргонимов (наименования делового объединения людей, например, названия партии) для дальнейшего применения тактики отождествления со значимыми ценностными ориентирами или положительными событиями:

A. Merkel: Wir, die Freunde und Mitglieder der Christlich Demokratischen Union, haben gemeinsam mit der CSU in den letzten Jahren gezeigt, dass wir bereit sind, Verantwortung zu tragen, $\langle\ldots . .>$. - Mbl, $\partial p y$ зья и члены Христианско-демократического союза, вместе с ХСС в последние годы показали, что мы готовы нести ответственность, <...>.

A. Merkel: <..> wenn es die Christlich Demokratische Union nicht gäbe, dann würden wir diese Gesetze nicht haben, und deshalb braucht es CDU, damit unsere Sicherheitsbehörden klar, und effektiv, und wirksam arbeiten könпеп. - ...если бы не было Христианско-демократического союза, тогда у нас не было бы этих законов, и поэтому ХДС необходим, чтобы наши органы государственной безопасности могли работать прозрачно, эффективно и действенно.

В приведённых высказываниях А. Меркель соотносит название партии с такими ценностными ориентирами, как ответственность, принятие актуальных законов и безопасность, которую реализуют органы государственной безопасности (Sicherheitsbehörden).

В приведённом ниже высказывании Х. Зеехофер использует антропоним Angela Merkel, связывая правление канцлера с благополучием Германии на данный момент. Для большего перлокутивного эффекта он употребляет лексическое повторение ging es nicht so:

12 Jahre CDU/CSU in Berlin unter Führung von Angela Merkel, und Deutschland ging es nicht so gut wie heute, liebe Freunde. Deutschland ging es nicht so. - 12 тет ХДС/ХСС в Берлине находится под правлением Ангелы Меркель и ещё никогда прежде жизнь в Германии не была такой хорочей как сегодня, дорогие друзья. 
Употребление антропонимов может также служить приёмом опоры на авторитетное мнение в рамках реализации тактики выделения «своего круга». За счёт данного приёма политический деятель придаёт своему высказыванию большую убедительность в глазах общественности. Так, $\mathrm{X}$. Зеехофер приводит цитату известного германского государственного деятеля и лидера ХСС (1961-1988 гг.) Франца Йозефа Штрауса:

Und ich wandle ein Wort von Franz Josef Strauß ab, „notfalls sind wir in Bayern die letzten Preußen, wenn es darum geht, Recht und Ordnung im unserem Land zu gewährleisten". - Я изменю одно слово Франиа Йозеба Штрауса «в случае необходимости мы в Баварии последние пруссаки, если речь идёт о гарантии сохранения права и порядка в нашей стране».

Приведённое выше высказывание направлено на единение с аудиторией для создания позитивного образа баварцев, которые поддерживают такие классические ценности Германии, как порядок и справедливость.

Использование геортонимов (наименование праздников, политических, исторических и военных событий) в речи политических деятелей также характерно для реализации тактики выделения «своего круга»:

H. Seehofer: Helmut Kohl ist der Kanzler der Deutschen Einheit, der diesen Wink der Geschichte ergriffen hat und die deutsche Einigung vollendet hat. Vergesst es nie. - Гельмут Коль - канилер единства Германии, который распознал знак истории и реализовал объединение Германии.

Объединение Германии в 1990 году стало значимым историческим событием и является важным ценностным ориентиром для германского общества.

В следующем высказывании Х. Зеехофер использует тактику отождествления со стабильностью и процветанием ФРГ:

Und das deutsche Jobwunder der letzten Jahre! Wir sind doch eine Insel der Stabilität. Wir sind ein Stabilitätsanker der ganzen Welt, die Bundesrepublik Deutschland. - A рекордное увеличение рабочих мест в последние годь!! Мы - остров стабильности. Мь являемся якорем стабильности для всего мира и для всей Германии.

Понятие das deutsche Jobwunder относится к фоновой лексике, включает в себя рост ВВП и снижение безработицы, и, как следствие, увеличение рабочих мест, начиная с 2005 года ${ }^{4}$ Х. Зеехофер прибегает к приёму лексического повторения местоимения wir с целью реализации концепта «свой круг». Кроме того, в данном высказывании оратор использует метафоры eine Insel der Stabilität, ein Stabilitätsanker der ganzen Welt для создания красочных образов и воздействия на массового адресата.

Речь X. Зеехофера часто носит лозунговый характер, для которого характерны краткие предложения, употребления лексических повторов, метафор или эллипсиса. За счёт этого подобные высказывания легко запоминаются и привлекают внимание массового адресата [15]:

Bayern muss Bayern bleiben. - Бавария должна оставаться Баварией.

Und dieses Ziel heißt: Bayern zuerst. Da lass ich von niemandem abbringen. - И этой целью является: Бавария - в первую очередь. И я никому не позволю это изменить.

Liebe Freunde, das alles ist Bayern. Bayern ist einzigartig, Bayern ist ein Paradies , <...>. - Дорогиe друзья, это всё Бавария. Бавария - единственная в своём роде. Бавария - это рай, <...>.

Для создания позитивного образа Германии и Баварии говорящий прибегает к лексическому повтору топонима Bayern и его отождествлению с лексикой с позитивной коннотацией einzigartig, Paradies, а также использует обращение к аудитории liebe Freunde, способствующее созданию доверительной атмосферы в ходе выступления.

Информационно-интерпретационная стратегия служит для информирования населения о значимых политических, социальных или экономических событиях и достижениях. Данная стратегия может иметь вспомогательную функцию для реализации самопрезентации или дискредитации оппонента в зависимости от интенций говорящего. В рамках данной стратегии поли-

\footnotetext{
4 https://www.statista.com/statistics/227005/unemployment-rate-in-germany/
} 
тические деятели часто употребляют фоновую лексику, корректное восприятие которой требует определённых экстралингвистических знаний со стороны адресата. К тактикам в рамках данной стратегии можно отнести тактику акцентирования положительной информации, тактику разъяснения, тактику признания существования проблемы, тактику указания на пути решения проблемы, тактику привлечения внимания к проблеме.

В приведённом ниже примере А. Меркель использует тактику акцентирования положительной информации для доказательства успешности проводимой политики:

Und diese Politik zeigt doch Erfolge. 50.000 neue Arbeitsplätze, Sozialversicherungspflichte seit 2005. И эта политика показывает результаты. 50.000 новых рабочих мест, обязательное соииальное страхование наёмного работника с 2005 года.

Одной из обсуждаемых тем в рамках “политической пепельной среды” 2017 года стала проблема обеспечения населения рабочими местами. Понятие «обязательное страхование наёмного работника ФРГ» (Sozialversicherungspflicht) включает в себя пенсионное страхование, страхование по безработице и страхование на случай болезни и является примером употребления фоновой лексики.

Наиболее острой проблемой, согласно опросу населения 5 в 2017 году была проблема миграции и интеграции беженцев и мигрантов. Эту тему в своём выступлении поднял Х. Зеехофер:

Liebe Freunde, wer bei uns leben will wegen Schutzbedarf und sich integrieren will, muss die deutsche Sprache lernen, muss sich an Recht und Ordnung halten, muss auch unsere Alltagskultur akzeptieren und akzeptieren, dass wir Bayern ein christliches Land sind, liebe Freunde! - Дорогие друзья, кто хочет жить унас, нуждаясь в защите, ижелает интегрироваться, должен учить немецкий язык, должен придерживаться законов и порядков, должен принимать нашу бытовую культуру и также должен принимать, что Бавария - христианская земля, дорогие друзья!

В приведённом высказывании оратор использует тактику указания на пути решения проблемы, подчёркивая необходимость интеграции мигрантов и признания особенностей культуры и религии Германии. Лексическая единица Alltagskultur относится, на наш взгляд, к фоновой лексике, повседневная культура в России и Германии имеют, безусловно, существенные отличия.

Одной из тем, затронутых политическими деятелями в своих выступлениях, стал вопрос будущего Германии. В этой связи в своей речи А. Меркель обозначила следующие важные пункты: пакет реформ «Агенда 2025» (Agenda 2025), цифровизация (die Digitalisierung), образование (die Bildung). Все эти понятия относятся к социально-политическим реалиям: Agenda 2025 относим к документонимам, а понятия die Digitalisierung и die Bildung - к фоновой лексике:

Deutschland 2025. Das muss unsere Agenda sein. Wie sieht dann Mecklenburg-Vorpommern aus? Was wollen wir mit der Digitalisierung machen? Wie muss die Bildung für unsere Kinder aussehen? - Германия 2025. Это должно стать темой нашего пакета реформ. Как будет выглядеть земля Мекленбург-Передняя Померания? Что мы собираемся делать с иифровизацией? Как должно выглядеть образование для наших детей?

В своём высказывании А. Меркель использует тактику привлечения внимания к проблеме с помощью употребления риторических вопросов.

В рамках обсуждения будущего Германии Х. Зеехофер также затрагивает тему пакета реформ «Агенда 2025» и цифровизации. Кроме того, политик подчёркивает важность сохранения рабочих мест для населения Германии с помощью тактики акцентирования положительной информации и тактики разъяснения:

Und deshalb werden wir in dieser Agenda 2025 auch alles tun, dass wir für die nächsten Jahre Jobs sichern. Und in einem ganz wichtigen Bereich der Digitalisierung aller Lebensbereiche heißt unser Motto Bits, Bytes, Bayern. Das sind unsere Anlegen, wir wollen da in die Weltspitze, liebe Freunde. Bits, Bytes, Bауетп. - И поэтому при создании «Агенда 2025» мы будем делать всё, чтобы сохранить рабочие места в последующие годы. В крайне важной области ицфровизации всех сфер жизни нашим де-

5 https://de.statista.com/statistik/daten/studie/2739/umfrage/ansicht-zu-den-wichtigsten-problemen-deutschlands/ 
визом является «Bits, Bytes, Bayern» (биты, байты, Бавария). Таковы наши иели, и мы хотим достигнуть здесь мировых рекордов, дорогие друзья.

В своей речи политик прибегает к лексическому повторению лозунга Bits, Bytes, Bayern, который связан с процессом перехода на цифровой формат всех сфер жизни в Баварии.

Главной целью стратегии дискредитации является подрыв доверия массового адресата к конкурирующей партии и её представителям, а также снижение влияния оппонентов в обществе. С помощью данной стратегии адресант стремится демонтировать позитивный образ оппонента и умалить его достижения в глазах потенциальных избирателей. Стратегия дискредитации реализуется с помощью тактики обвинения, а также тактики оскорбления и издёвки. Употребление ценностных концептов с целью дискредитации оппонента реализуется за счёт противопоставления действий конкурирующей партии ценностям общества.

Одной из значимых ценностей германского общества, тесно связанной с проблемой миграции, является толерантность. В концепт «толерантность», по утверждению С.С. Тахтаровой, входят два основных признака: наличие культурных различий и умение принимать их в других представителях общества [11]. К тактике обвинения в неследовании ценностным ориентирам прибегает, например, X. Зеехофер:

Für uns gibt es null Toleranz für Ausländerhass, für Antisemitismus und Hassparolen. Und mit rechtsradikalen dummen Fragen haben wir schon gar nichts gemeinsam. - У нас нет терпимости в отнотении ненависти к иностраниам, антисемитизма и разжигания ненависти. И с этими ультраправыми глупыми вопросами у нас совершенно нет ничего общего.

Политик употребляет концепт null Toleranz в отношении проявлении ненависти к иностранцам и антисемитизма и связывает данные понятия с вопросами от представителей правых партий. Лексические единицы Ausländerhass, Antisemitismus, Hassparolen относятся к фоновой лексике, поскольку имеют отношение к историческим событиям в Германии в период 1939-1945 гг. Данное высказывание включает в себя также приём дистанцирования, который реализуется за счёт инверсии для акцентуации внимания аудитории и усилительной частицы gar в словосочетании gar nichts gemeinsam.

А. Меркель употребляет тактику обвинения с целью указания на неспособность членов СДПГ к сотрудничеству:

Die Sozialdemokraten haben bis heute noch nicht die Kraft, sich zu dem zu bekennen, was auch dazu mitgeholfen hat, dass wir das heute erreichen konnten, nämlich zu der Agenda 2010. - Социал-демократы до сих пор недостаточно сильны, чтобы признать свою ответственность, и это также помогло нам достигнуть принятия реформ «Агенды 2010».

Для реализации негативной оценки несогласия СДПГ с пакетом реформ «Агенда 2010» оратор употребляет эргоним die Sozialdemokraten и документоним Agenda 2010.

Одним из характерных приёмов стратегии дискредитации, при использовании тактики оскорбления и издёвки, является приём навешивания ярлыков, который может реализовываться за счёт антропонимов:

H. Seehofer: Aber, wenn er mit dieser Politik fortführt, werden wir ihm diese Mogelpackungen nicht mehr durchgehen lassen. Denn heißt Martin Schulz künftig nicht mehr Martin Schulz, sondern Martin der Schummler. - Но, если он продолжит данную политическую линию, мы больше не допустим повторения его красивых слов. Поскольку тогда в будущем его будут звать не Мартин Шульи, а Мартин Шулер.

Этот приём является эффективным способом воздействия на адресата за счёт использования лексики с эмоционально-экспрессивной окраской с отрицательной оценкой. В данном высказывании политик уличает своего противника во лжи, называя его «лжецом» (der Schummler), проводя некую аналогию с его фамилией (Schulz).

Манипулятивная стратегия, как и стратегия дискредитации, направлена на очернение положительного образа оппонента и конкурирующей партии. Отличительной чертой манипуляции является скрытое побуждение адресата к желаемым действиям, в то время как дискредитация считается проявлением речевой агрессии, нацеленной на оскорбление [10]. 
К способам реализации коммуникативной стратегии манипуляции лингвисты причисляют псевдоаргументацию, имитацию авторитетности и силы [6], приёмы демагогии, тактики гиперболизации, компрометации, утрирования, ложного обобщения, инсинуации [9] и др.

В своих высказываниях, направленных против партии «Союз 90/Зелёные», Х. Зеехофер прибегает к тактике ложных обвинений (инсинуаций):

Ich kann euch nur sagen: das Verhalten der Grünen ist der Gipfel der Schäbigkeit und die Grünen sind das wahre Sicherheitsrisiko für unser Land. - Я могу сказать вам только одно: поведение «Зелёньх»это вершина подлости, а партия «Зелёные» представляет настоящую угрозу безопасности для намей страны.

Ich wiederhole, die Grünen sind ein Sicherheitsrisiko für unser Land und solange sie so denken, kommt für die CSU die Grünen als Koalitionspartner nicht in Frage, mit denen wollen wir nicht. - Я повторяю, «Зелёные» - это угроза безопасности для нашей страны, и пока они обладают таким образом мышления, партия «Зелёные» не может быть коалиционным партнёром для ХСС, мы этого не хотим.

В обоих высказываниях политик использует перформатив в начале предложений (ich kann euch sagen, ich wiederhole), лексические повторения слова с негативной коннотацией Sicherheitsrisiko, фразеологизм der Gipfel der Schäbigkeit, а также притяжательные и личные местоимения unser, wir. Все перечисленные языковые средства служат для создания яркого негативного образа конкурирующей партии и реализации концепта «свои-чужие».

Агитационная стратегия так же, как и информационно-интерпретативная, может использоваться для усиления воздействия от речевых стратегий самопрезентации или дискредитации. К тактикам указанной стратегии можно отнести тактику призыва и тактику обещания.

В приведённом ниже высказывании Х. Зеехофер прибегает к тактике призыва, реализуя концепт «свои-чужие» для противопоставления граждан (das Bürgerliche) и коалиции СДПГ, «Левых» и «Зелёных»:

Das Bürgerliche muss jetzt aufstehen und kämpfen gegen Rot-Rot-Grün. - Граждане должны встать и бороться против коалиции СДПГ, «Левых» и «Зелёных».

Для обозначения данной коалиции политик прибегает к метафорическому образу, обозначая партии по их цвету. Подобное обозначение партий является типичным для политического дискурса Германии. Так, после выборов 2017 года, одним из возможных форматов коалиции была «Коалиция Ямайка» (Jamaika Koalition), названная так по совпадению цветовой символики ХДС/ ХCC (schwarz), «Союз 90/Зелёные» (grün) и СвДП (gelb) и цветов государственного флага Ямайки (чёрный, зелёный, жёлтый).

В следующем примере политик призывает массового адресата гордиться достижениями правящего блока, используя форму повелительного наклонения (seid stolz) и перформатив (deshalb bitte ich):

H. Seehofer: Liebe Freunde, das ist doch alles mit CDU/CSU verbunden. Und deshalb bitte ich alle Anhänger, alle Freunde: seid stolz auf eure Union, was sie für Deutschland erreicht hat. - Дорогие друзья, всё это связано с ХДС/ХСС. И поэтому я прошу всех приверженцев наших взглядов, всех друзей: гордитесь вашей партией и тем, что она сделала для Германии.

Для создания позитивного образа блока ХДС/ХСС выступающий использует приём гиперболизации с помощью лексемы alles, указывая тем самым, что все достижения связаны с сотрудничеством этих двух партий. В данном высказывании употребляется топоним Deutschland в контексте тех позитивных действий, которые привели Германию к успеху. Создание атмосферы сближения с массовым адресатом достигается за счёт обращений liebe Freunde, alle Anhänger, alle Freunde.

Тактика обещания служит для создания позитивного образа политического деятеля и гарантии положительных перспектив в будущем. Как правило, данная тактика реализуется с помощью форм будущего времени:

H. Seehofer: Ich gebe in Passau diese Garantie, dass das was ich euch heute gesagt habe, von der CSU solange verfolgt wird, bis es auch in der Realität Praxis ist, meine Damen und Herren. -В Пассау я даю 
гарантию, что всё сказанное сегодня будет контролироваться со стороны ХСС до тех пор, пока не станет практикой в реальности.

Х. Зеехофер связывает название ХСС и правящего блока ХДС/ХСС с осуществлением данных ранее обещаний, а также с будущим Германии в целом. В своей речи политик использует перформатив ich gebe diese Garantie, а также гендерно-маркированную лексику (meine Damen und Herren, liebe Freunde) с целью привлечения внимания адресата.

\section{Выводы}

В ходе анализа публичных выступлений лидеров блока ХДС/ХСС А. Меркель и Х. Зеехофера были определены основные акценты предвыборной кампании 2017 года: миграция и толерантность, безопасность и криминогенная обстановка, будущее Германии, образование, работа и социальная сфера.

При этом А. Меркель в своей речи не касалась темы миграции и толерантности, делая упор на проблемы образования, новые реформы и будущее Германии. Х. Зеехофер в своём выступлении обратил внимание на достижения блока ХДС/ХСС, а также на проблемы безработицы и интеграции мигрантов.

Проведённый анализ на материале двух выступлений подтверждает утверждение Т.С. Комиссаровой, что речь германских политиков отличается выраженной оценочностью суждений, метафоричностью и вербальной агрессивностью [7].

Для реализации своих коммуникативных намерений политики прибегали к различным речевым стратегиям. Так, для выступления А. Меркель характерно употребление стратегии самопрезентации, стратегии дискредитации и информативно-интерпретационной стратегии. Х. Зеехофер, помимо перечисленных выше стратегий, прибегал также к манипулятивной и агитационной стратегии. Речь X. Зеехофера часто носила лозунговый характер, для его выступления характерно употребление обращений к массовому адресату liebe Freunde с целью включения аудиторию в «свой круг».

Реализация речевых стратегий осуществлялась при помощи разноуровневых языковых средств. Среди лексических средств было выявлено употребление фразеологизмов, ярлыков, лексических усилителей. Монологическая речь ораторов отличается распространённым синтаксисом, однако встречаются также краткие нераспространённые предложения, носящие лозунговый характер. Среди стилистических средств можно выделить употребление метафор и сарказма.

Помимо упомянутых языковых средств, политические деятели активно использовали КМЛ. Так, для реализации стратегий самопрезентации и дискредитации А. Меркель и Х. Зеехофер употребляли эргонимы, антропонимы, документонимы, геортонимы, топонимы. В данном исследовании мы опирались на классификацию М.А. Чигашевой, М.А. Елизарьевой и Т.С. Лариной [14]. Геортонимы и топонимы часто употребляются в рамках лингвокультурного концепта «свой круг». В рамках стратегии самовосхваления эргонимы и антропонимы могут использоваться для реализации тактики отождествления партии с позитивными изменениями, а также для привлечения внимания общественности к достижениям партии и её представителей, в то время как при использовании стратегии дискредитации эргонимы и антропонимы могут служить для реализации речевых действий обвинения и приёма навешивания ярлыков в рамках тактики оскорбления и издёвки. Также за счёт лексики, относящейся к наименованиям культурно-исторических событий или географическим наименованиям, политические деятели придают своим высказываниям лозунговый характер.

Особое значение в выступлениях политиков имеет фоновая лексика, для понимания которой адресату необходимы экстралингвистические знания. КМЛ встречается во многих высказываниях политиков и напрямую связана с ценностными ориентирами и языковой картиной мира германского общества. 
Таким образом, употребление КМЛ можно считать довольно успешным приёмом реализации различных речевых стратегий, к которому прибегают партийные лидеры в ходе публичных выступлений, что способствует формированию собственного позитивного политического имиджа и нивелирует достижения оппонентов в глазах потенциального избирателя за счёт создания нужного эмоционального настроя у массового адресата.

(C) Крячкова А.П., 2020

\section{Список литературы}

1. Алешина Е.Ю. Публичный политический дискурс конфликтной ситуации: монография. М.: Прометей, 2015. С.45

2. Верещагин Е.М., Костомаров В.Г. Язык и культура: Лингвострановедение в преподавании русского языка как иностранного. 4-е изд., перераб. и доп. М.: Рус. яз., 1990. 246 с.

3. Елизарова Г.В. Культура и обучение иностранным языкам. СПб.: КАРО. 2005. 55 с.

4. Зигманн Ж.В. Структура современного политического дискурса: речевые жанры и речевые стратегии. Автореф. дис. ... канд. филол. наук. М., 2003. 24 с.

5. Иссерс О.С. Коммуникативные стратегии и тактики русской речи: монография. Омск: ОГУ, 1999. 285 с.

6. Карасик В.И. Языковой круг: личность, концепты, дискурс. Монография. Волгоград: Перемена, 2002. 477 с.

7. Комисарова Т.С. Механизмы речевого воздействия и их реализация в политическом дискурсе: на материале речей Г. Шрёдера: дис. ... канд. филол. наук. Орел, 2008250 с.

8. Паршин П.Б. Лингвистические методы концептуальной реконструкции // Системные исследования: Ежегодник: 1986. М.: Наука, 1987. 403 с.

9. Паршина О.Н. Стратегии и тактики речевого поведения современной политической элиты России: дис. ... д-ра филол. наук. Саратов, 2005. 325c.

10. Седов К.Ф. Агрессия как вид речевого воздействия // Прямая и непрямая коммуникация: Сб. науч. тр. Саратов: Издво ГосУНЦ «Колледж», 2003. С. 196-212.

11. Тахтарова С.С. Концепт Toleranz в немецкой лингвокультуре // Вопросы когнитивной лингвистики. 2008. № 1 (014). C. 64-71.

12. Телия В.Н. Основные постулаты лингвокультурологии //Филология и культура: материалы II Международной конференции, 12-14 мая 1999 г.: в 3 частях / отв. ред. Н.Н. Болдырев. Тамбов: Изд-во ТГУ, 1999. Часть 3. С. 14-15.

13. Томахин Г.Д. Реалии американизмы. Пособие по страноведению. М.: Высшая школа. 1988. 240 с.

14. Чигашева М.А. Национально-культурная специфика политического языка лидеров блока ХДС/ХСС. /М.А. Чигашева, М.А. Елизарьева, Т.С. Ларина/ Полис. Политические исследования. 2020. № 4. С. 152-165.

15. Чудинов А.П. Метафорическая мозаика в современной политической коммуникации: Монография / Урал. гос. пед. ун-т. Екатеринбург, 2003. 248 с.

16. Шейгал Е.И. Семиотика политического дискурса. М.: Гнозис, 2004. 324с.

\section{References}

1. Aleshina, E.Yu. Publichny politicheskii diskurs konfliktnoi situatsii: monografiia [The public political discourse of the conflict: monograph.]. M.: Prometei, 2015. p. 45.

2. Vereshchagin, E.M., Kostomarov, V.G. Iazyk i kul'tura: Lingvostranovedenie v prepodavanii russkogo iazyka kak inostrannogo [Language and culture: Linguistic and regional studies in the teaching of Russian as a foreign language.] 4-e izd., pererab. i dop. M.: Rus. yaz. 1990. 246 p.

3. Elizarova, G.V. Kul'tura i obuchenie inostrannym iazykam [Culture and teaching foreign languages]. SPb.: KARO. 2005. p. 55.

4. Sigmann, ZH.V. Struktura sovremennogo politicheskogo diskursa: rechevye zhanry i rechevye strategii. Avtoref. dis. ... kand. filol. nauk [The structure of modern political discourse: speech genres and speech strategies]. M., 2003. 24p.

5. Issers, O.S. Kommunikativnye strategii i taktiki russkoi rechi: monografiia [Communicative strategies and tactics of Russian speech: monograph.]. Omsk: OGU, 1999. 285 p.

6. Karasik, V.I. Iazykovoi krug: lichnost', kontsepty, diskurs. Monografiia [Language circle: personality, concepts, discourse. Monograph]. Volgograd: Peremena, 2002. 477 p.

7. Komisarova, T.S. Mekhanizmy rechevogo vozdeistviia i ikh realizatsiia v politicheskom diskurse: na materiale rechei G. Shryodera [The mechanisms of speech influence and their implementation in political discourse: on the material of speeches by G. Schroeder]: diss...kand. filol. nauk. Orel, 2008. 250p.

8. Parshin, P.B. Lingvisticheskie metody kontseptual'noi rekonstruktsii // Sistemnye issledovaniia [Linguistic methods of conceptual reconstruction // System Studies]. Ezhegodnik: 1986. M.: Nauka, 1987. 403 p.

9. Parshina, O.N. Strategii i taktiki rechevogo povedeniia sovremennoi politicheskoi elity Rossii: diss. ... d-ra filol. nauk [Strategies and tactics of speech behavior of the modern political elite of Russia]. Saratov, 2005. 325 p.

10. Sedov, K.F. Agressiia kak vid rechevogo vozdeistviia // Priamaia i nepriamaia kommunikatsiia [Aggression as a form of speech exposure // Direct and indirect communication]: Sb. nauch. tr. Saratov: Izd-vo GosUNC «Kolledzh», 2003. pp. 196-212. 
11. Takhtarova, S.S. Kontsept Toleranz v nemetskoi lingvokul'ture // Voprosy kognitivnoi lingvistiki [The Toleranz Concept in German Linguistic Culture // Questions of Cognitive Linguistics]. 2008. № 1 (014). pp. 64-71.

12. Teliya, V.N. Osnovnye postulaty lingvokul'turologii // Filologiia i kul'tura: materialy II Mezhdunarodnoi konferentsii, 12-14 maia 1999 g.: 33 chastyakh / otv. red. N.N. Boldyrev [Basic postulates of linguoculturology // Philology and Culture: Materials of the II International Conference, May 12-14, 1999: in 3 parts]. Tambov: Izd-vo TGU, 1999. CHast' 3. pp. 14-15.

13. Tomakhin, G.D. Realii amerikanizmy. Posobie po stranovedeniiu [The realities of Americanisms. The allowance for regional geography.]. M.: Vysshaia shkola. 1988. 240 p.

14. Chigasheva, M.A. et al. Natsional'no-kulturnaia spetsifika politicheskogo iazyka liderov bloka HDS/HSS [National-Cultural Specificity of the Political Language of the CDU/CSU-Leaders]. / M.A. Chigasheva, M.A. Elizar'eva, T.S. Larina Polis. Politicheskie issledovaniia. 2020. № 4. pp. 152-165.

15. Chudinov, A.P. Metaforicheskaia mozaika v sovremennoi politicheskoi kommunikatsii: Monografiia [Metaphorical Mosaic in Contemporary Political Communication: Monograph] / Ural. gos. ped. un-t. Ekaterinburg, 2003. 248 p.

16. Sheigal, E.I. Semiotika politicheskogo diskursa [Semiotics of Political Discourse]. M.: Gnozis, 2004. 324 p.

\title{
Сведения об авторе:
}

Крячкова Александра Павловна - кандидат филологических наук, преподаватель кафедры немецкого языка МГИМО (Россия, Москва). Сфера научных и профессиональных интересов: лингвопрагматика, политическая лингвистика, дискурс-анализ.

E-mail: kryachkova.ap@yandex.ru

Конфликт интересов: Автор заявляет об отсутствии конфликта интересов.

\author{
About the author: \\ Aleksandra P. Kryachkova - PhD, Lecturer of the German Language Department, MGIMO University (Mos- \\ cow, Russia). Spheres of research and professional interest: linguo-pragmatics, discourse analysis, political lin- \\ guistics. \\ E-mail: kryachkova.ap@yandex.ru \\ Conflicts of interest: The author declares absence of conflicts of interest.
}

